\title{
Sperm-0viduct Interaction Factors that Compromise Fertility of Frozen Stallion Semen
}

\author{
Bonometti $S^{2}$, Menarim B ${ }^{3}$, Orlandi $C^{4}$, Uberti B ${ }^{5}$, Ramírez-Reveco $\mathrm{A}^{1 *}$ \\ ${ }^{1}$ Laboratorio de Criobiología y Análisis de Funcionalidad Espermática, Instituto de Ciencia Animal, Facultad de Ciencias Veterinarias, Universidad \\ Austral de Chile, Chile
}

${ }^{2}$ Department of Animal and Poultry Sciences - College of Agricultural and Life Sciences - Virginia Tech

${ }^{3}$ Department of Large Animal Clinical Sciences - Virginia-Maryland College of Veterinary Medicine - Virginia Tech

${ }^{4}$ Sao Paulo State University-UNESP, Brazil

${ }^{5}$ Instituto de Ciencias Clínicas Veterinarias, Facultad de Ciencias Veterinarias, Universidad Austral de Chile, Chile

Submission: October 23, 2017; Published: December 22, 2017

*Corresponding author: Alfredo Ramírez Reveco, Instituto de Ciencia Animal, Facultad de Ciencias Veterinarias, Universidad Austral de Chile, Campus Isla Teja, Valdivia, Chile, Tel: (56) 63-2293065; Fax: (56) 63-2221488; Email: alfredoramirez@uach.cl

Abstract

The cryopreservation procedure changes the integrity and functionality of sperm, affecting their longevity and the ability to fertilize the oocyte. Moreover, some of those changes could be alter the physiologic interactions between the sperm and the oviductal epithelial cells prior to fertilization, placing further limitations and challenges on frozen-thawed stallion sperm. For fertilization to occur, a sperm subpopulation should be survive in uterine environment and be transported to oviduct, the tubular epithelium that regulate the sperm capacitation process in tuning with the ovulation and later oocyte fecundation.

Factors affecting sperm-oviduct interactions in equine and findings in other mammals suggest that this interaction is highly conserved. However, there are differences between species and this interaction may assist to explain the idiopathic infertility associated with the use of frozen equine semen. Molecular changes to the spermatozoa during the cryopreservation process may affect sperm morphology, integrity of membranes and sperm motility. Likely, some of those changes are related to the cryptic behavior of sperm before and after of their interaction with the oviduct. The aim of present review is describing the interactions involved in normal sperm-oviduct binding, and implications of cryopreservation process in normal function of stallion sperm in the oviduct.

Keywords: Sperm; Cryopreservation; Oocyte; Artificial insemination

Abbreviations: AI: Artificial Insemination; OEC: Oviductal Epithelial Cells; PMN: Polymorphonuclear Cells; ZP: Zona Pellucida; SP: Seminal Plasma; AR: Acrosomal Reaction; HA: Sodium Hyaluronate; GAG: Glycosaminoglycan; HE: Heparin; OSG: Oviduct Specific Glycoproteins; OVS: Oviductosomes; EVs: Extracellular Vesicles; CRISP: Cysteine-Rich Secretory Proteins; BSPP: Bovine Seminal Plasma Proteins; BSP: Binder of Sperm; HSP: Horse Seminal Plasma Proteins

\section{Introduction}

The equine industry has experienced tremendous development in the last decades considerably favored by the incorporation of reproductive biotechnologies, particularly by the massive use of artificial insemination (AI) with fresh, chilled or frozen semen. Amongst those biotechnologies, the use of sperm cryopreservation for AI demonstrates this great impact allowing sperm to be preserved viable for long periods of time, therefore optimizing the use of genetically superior stallions $[1,2]$.

Currently, AI plays a leading role in breeding programs of several breeds [3]. However, breeds such as thoroughbred still do not accept registration of artificially produced foals [4]. Although sperm cryopreservation allows storage of sperm cells for an undefined time, it has been evidenced that semen of just $25-30 \%$ of stallions adequately tolerate cryopreservation $[1,3]$ and experience is required in order to freeze and inseminate successfully [2,3]. Due to wide interest on the application of such biotechnology, the number of studies that characterize sperm function, its response to cryopreservation and spermatic physiology in the mare's reproductive tract has increased [2]. For the sperms reach the oviduct, with its functional and structural characteristics intact, sperm cells need to tolerate several physical and chemical events during semen handling: collection, dilution, centrifugation, suspension, cooling, freezing, thawing and insemination. Once in the oviduct of the mare, the sperm cells should to experience a series of functional reactions that prepare them to fertilize the oocyte.

The oviduct acts as a spermatic reservoir delaying the process of capacitation, which is dependent on the interaction between sperm and oviductal epithelial cells (OEC) [5,6] and 


\section{Global Journal of Reproductive Medicine}

the binding of sperm to OEC protects the spermatozoa from phagocytosis by polymorphonuclear cells (PMN) while keeping them viable $[7,8]$ and facilitating the process of capacitation prior to fertilization. For a full physiologic interaction between sperm and oviductal cells to develop, it is necessary that sperm arrive in the isthmus with their plasma and acrosomal membrane intact. Spermatozoa with damaged membranes and/or amorphous morphology interact with OEC to a lesser degree than those that are normal [7]. A thorough knowledge of cryodamage through the cryopreservation process is essential to the development of techniques that improve the results of artificial insemination with frozen semen, thereby providing better opportunities for the equine industry.

\section{Phisiological changes before and after sperm ejaculation}

In mammals, spermatozoa and oocytes must fuse to create a zygote. Fusion critically depends on the complex changes undergone by spermatic membranes. When spermatozoa enter the epididymis, they are not yet completely "mature" and significant changes occur in both, nuclear chromatin and plasma membrane during epididymal transit. Some of these changes include the secretion, modification and adsorption of proteins and lipids. Sperm cells only completely mature once they reach the tail of the epididymis. After leaving the testicular parenchyma, spermatozoa lose the ability to synthesize plasma membrane lipids and proteins. The reason for these superficial alterations is not completely understood [9], but studies have described that equine seminal plasma proteins may participate in the first steps of the fertilization sequence such as modulation of capacitation, establishment of an oviductal spermatic reservoir and gamete interaction [10]. Following ejaculation mammalian spermatozoa must undergo a series of membrane changes, both structural and metabolic, before acquiring the ability to bind to the zona pellucida (ZP) and fertilize the oocyte. These changes are known as capacitation and occur within the oviduct and ideally as close as possible to ovulation [11].

\section{Response of the sperm cell to freezing}

The process of freezing semen entails a series of physical and chemical changes in the sperm cell, affecting their integrity and function and therefore their capacity to fertilize the oocyte [12]. One stage prior to freezing is chilling, which reduces the temperature of semen from body temperature $\left(37^{\circ} \mathrm{C}\right)$ to chilled temperature $\left(5^{\circ} \mathrm{C}\right)$. This thermal reduction leads to a change in plasma membrane lipids from a crystalline liquid to a gel state, impeding the normal dynamic functioning of plasma membrane proteins and phospholipids, causing an electrolyte imbalance [13].

During the process of chilling, there is a stage of thermal shock termed "cold shock", which consists of a series of alterations suffered by spermatozoa when subjected to a quick decrease in temperature (from $18-20{ }^{\circ} \mathrm{C}$ to $5{ }^{\circ} \mathrm{C}$ ) $[2,13]$. The thermal shock depends not only on the absolute change of temperature but also on the rate of temperature reduction and can cause irreparable damage to the spermatozoa including abnormal motility patterns (circling), rapid loss of motility, acrosomal damage, plasma membrane damage, metabolic reductions and loss of intracellular components [2]. Some of these damages correspond to plasma membrane changes, during the transition from the liquid to the gel state, which affects the viability and functional integrity of the spermatozoa [13]. These changes may be minimized by adding extenders immediately after semen collection, centrifugation and removal of seminal plasma (SP) and by controlling the rate of temperature reduction [2].

The plasma membrane surrounds the entire spermatozoon and separates the cytosol from the extracellular medium. This membrane is composed of lipids and proteins [1]. There are two kinds of lipids: phospholipids, which are most abundant, and cholesterol, which fills the spaces between the fatty acid chains in phospholipids, thus stabilizing the plasma membrane. Proteins are inserted between phospholipids, representing approximately $50 \%$ of the weight of the plasma membrane, being sorted as integral or peripheral. Proteins are usually channels and membrane receptors for ions and molecules. Many proteins contain carbohydrate chains called glycoproteins [1] and plasma membrane proteins may be involved in the process of interaction between spermatozoa and the oviduct.

The plasma membrane components have lateral movements, generally spaced randomly. This is possible because at room temperature the plasma membrane is in a liquid crystalline state [1]. Damage to the plasma membrane may occur during chilling, as lipids adopt a gel state, inhibiting the natural flexibility of the membrane and may cause "tears" allowing ions to move in or out of the cell or inhibiting the activity of membrane proteins [13]. When the cell membrane of sperm is altered, sodium and calcium ions entering the cells are removed by active transport. At $5{ }^{\circ} \mathrm{C}$, permeability to calcium is significantly increased, overrunning the removal capacity of the cell's calcium pumps. This leads to a toxic accumulation of calcium within the spermatozoon [3]. Therefore, preserving the integrity of the cell membrane is essential for the survival of spermatozoa.

Freezing allows preservation of cells at extremely low temperatures $\left(-196^{\circ} \mathrm{C}\right)$, with an inactive metabolism. However, for many years, it was believed that phenomena such as dehydration, membrane distortion and ice crystal formation (intra or extracellular) occurred during the second critical stage of freezing (between -15 and $-60^{\circ} \mathrm{C}$ ) [3]. Morris et al. [14] measured the formation of ice by means of differential scanning calorimetry. This technique was used to prove that within the range of temperatures currently used for freezing semen, no ice crystals form intracellularly in human and animal spermatozoa. Therefore, most damage is almost certainly caused by osmotic stress, especially during thawing. This occurs for two reasons. Firstly, the intracellular medium has a high protein content, which when combined with osmotic shrinking that occurs due to the presence of extracellular ice, leads to vitrification of the intracellular medium. Secondly, when temperature reduction 


\section{Global Journal of Reproductive Medicine}

occurs at a high rate, an osmotic imbalance entails due to extracellular ice crystals formation that limits diffusion. Thus, spermatozoa subjected to cryopreservation suffer osmotic shock during the thawing process leading to cell damage [15].

\section{Changes induced by the process of cryopreservation}

The cryopreservation process, which includes cooling, freezing and thawing, can harm spermatic function. Damage to spermatozoa caused by cryopreservation is multifactorial. Premature induction of capacitation, or cryocapacitation, reported in several species including the horse [16], can cause damage. Frozen/thawed spermatozoa are more susceptible to capacitation induction, which may explain the shortened life expectancy in comparison to fresh semen. Besides this, they demonstrate an impaired ability to bind to the OEC [17]. Considering that the mare estrous cycle is relatively long, the reduced longevity of cryopreserved semen makes careful timing of insemination a critical requirement [18].

Normal spermatozoa, which are viable, motile, morphologically normal [19] and have not yet undergone capacitation [16], bind to the OEC. A suppression of these events related to capacitation can be due to calcium influx to the cell and phosphorylation to sperm proteins [20]. Sperm cells bound to the OEC are required to be freed to initiate the process of capacitation. This phenomenon occurs due to changes in the bicarbonate/CO2 content in oviductal secretions [21-23]. If capacitation or the acrosomal reaction (AR) occurs prior to insemination due to advanced membrane instability, the most likely result is the spermatozoa's impaired capacity to interact with the OEC, penetrate ZP and fertilize the oocyte [16].

\section{Oviductal physiology of the mare}

The mammalian oviduct has essential roles in mammalian reproduction. The OEC create a unique environment for the transport and maturation of gametes, fertilization and early embryonic development [6]. A functional level, the oviduct is divided into three distinct anatomical regions. The most cranial is the infundibulum, responsible for oocyte transport after ovulation; the second region is the ampulla, a dilated tubular region, where fertilization takes place; and the isthmus is the last portion of the oviduct involved in the transport of gametes and embryos [24]. The latter region, the ovituctal isthmus, also functions as a spermatic reservoir and has two main roles as a spermatic filter to reduce the amount of sperm reaching the ampulla (site of fertilization) and also as a reservoir, responsible for storing sperm prior to ovulation $[19,25]$.

The oviduct is formed by a simple columnar epithelium, which is composed of two types of cells, ciliated and non-ciliated [19]. Non-ciliated cells are secretory cells that participate in the synthesis and release of glycoproteins that are solubilized in the oviductal fluid, along with a selective serum transudate [26]. Some glycoproteins have been associated with the surface of spermatozoa and the oocyte and may play an important role in fertilization and early embryonic development. In the isthmus, three different kinds of granules have been observed, suggesting there may be differences in secretory activities [6]. Ciliated cells play an important role in the transport of germinal cells [26] and they are found in higher proportion than nonciliated cells throughout the oviduct. The number of ciliated cells increases from the fimbriae of the infundibulum to the ampulla but decrease in number within the isthmus [6]. The oviductal structures have different types of mucosa. The isthmus has a narrow lumen and mucosal folds, which are unbranched and short, the ampulla contains a large number of branched folds and finally, the infundibulum has finger-like mucosal folds [6].

Studies performed by Aguilar et al. [26], gland-like structures were identified by histological examination of the equine oviduct. These gland-like structures were formed by both non-ciliated and ciliated epithelial cells. These structures were found in different quantity both within the folds of the mucosa and in the periphery of the mucosa, were they were more abundant. In addition, the concentrations of these glands were diminished from ampulla to the isthmus. Cells in the isthmus have a denser cytoplasm than other oviductal segments and the cilia of these cells are surrounded by a thick extracellular matrix. This substance is composed of material secreted by the lumen of non-ciliated cells and may be responsible for the union of spermatozoa and cilia thus turning the oviduct into a reservoir of spermatozoa in several mammalian species, including horses [6]. This reservoir is able to maintain spermatic fertility and regulate capacitation and hyperactivation of spermatic motility in order to preserve effective spermatozoa for the time of ovulation $[5,6]$.

The oviduct undergoes some changes during the estrous cycle in many species. Moreover, the oscillation of ovarian steroid concentrations can be responsible for these changes, producing composition variations of the secretions of the oviduct. These changes include a variation in the proportion of non-ciliated and ciliated cells and changes in the cells height [27]. Analysis of the composition of oviductal secretions in some mammals indicates that oviductal fluid is biochemically complex and that proteins are an important component of these secretions [28]. In the mare, it is composed of serum ultra filtrates, follicular fluid, and products of specific oviductal secretory cells. Oviductal cell secretion increases during the follicular phase, in response to stimulation by estrogen and LH [29].

\section{Oviductal secretions and sperm function}

Different proteins originating from oviductal secretions have been described. A study in the reproductive tract of the mare revealed the presence of CD 44 (cluster of differentiation 44), a adhesion protein that enable the interaction between cells and its micro-environment [30], and is one of the specific receptors for sodium hyaluronate (HA). The glycosaminoglycan (GAG) HA is a major component of the extracellular matrix of mammalian cells. In the reproductive tract of different mammals, HA-CD 44 has been showed; however its specific role has not 


\section{Global Journal of Reproductive Medicine}

yet been defined. In sows and cows, it has been reported to be important in oocyte maturation and ovulation signaling [31]. In mares, CD 44 is distributed all over the uterine epithelium and oviduct and inconsistently in granulose and cumulus oophorous cells. Furthermore, an increased expression of CD44 during ovarian follicular development has been observed, as well as a progressive decrease of its expression in the oviduct from the infundibulum to the isthmus. The variable expression of CD44 during the follicular dynamic wave suggests that the HACD44 system is involved in several reproductive events such as ovulation, movement and storage of spermatozoa [29].

Oviductal secretions play an important role preparing spermatozoa for fertilization, through the induction of capacitation and acrosomal reactions. Reproductive tract secretions include GAG, which are directly linked to these processes [32]. In canines, GAGs are also called capacitation factors, since they can promote spermatic capacitation by binding and removing seminal plasma proteins adhered to spermatic plasma membranes, inhibiting capacitation [33]. Heparin (HE) belongs to the GAG family, that to functional level induce in vitro capacitation of bovine, caprine and equine spermatozoa. HE binds to bovine spermatozoa through protein unions located on the plasma membrane, producing an increase in protein phosphorylation, the influx of calcium into the cell, and an increase of intracellular $\mathrm{pH}$, all of which lead to the induction of capacitation [33]. A group of Oviduct specific glycoproteins (OSG) or oviductins has been described in mares, cows, hamsters, rabbits, women and sheep. These glycoproteins have been shown to increase during the follicular phase $[29,30]$ and have also been found associated to the oocyte, embryo and spermatozoa $[28,29]$. An in-vitro study in bovine showed that spermatozoa treated with OSG became capacitated, remained motile and viable and showed increased rates of fertilization and embryo development compared to standard in-vitro fertilization (IVF) conditions [29]. Oocytes pre-treated with OSG displayed improved fertilization rates and embryo development, even though rates of sperm binding to the zona pellucida were reduced [29]. Other studies showed that hamster oviductin bound to acrosomal region and enhances sperm capacitation [34,35]. Interestingly, also has been reported that the sperm-binding sites of hamster oviduct in were related to the sperm capacitation status and the acrosome reaction [36].

Osteopontin, another glycoprotein present in oviductal secretions, has been detected in bovine [37] and equine [29]. This protein, has showed have a variable expression throughout the estrous cycle [37] and stimulates fertilization and embryo development in cows [28]. Moreover, has been reported that spermatic adhesion to the oocyte, fertilization rates and embryo bovine development rates were significantly higher when oocytes were incubated in oviductal fluid containing osteopontin antibodies, before in-vitro fertilization[28], suggestive of a regulation role in those process. Another study in mares revealed a slight increase in the in-vitro fertilization rates adding bovine osteopont in to equine gametes [30], however these results were not significant. At present, the specific roles for oviductin and osteopontin and the effects on sperm function in oviduct of the mare has not yet been established [30]. Glycodelins, is a protein family of at least four isoforms (S, A, F and C), that have been detected in the human oviduct [38]. Several effects associated to glycodelins have been described on sperm function, [39] including the inhibition of sperm capacitation in human and hamster and gamete interaction in human (glycodelin A [40,41] and $F$ [42]). The suppression of progesterone-induced AR in human sperm associated to glycodelin $\mathrm{F}$ has been reported [43], suggesting its role in preventing a premature acrosome reaction [38].

Recently, Al-Dossary et al. [44] reported that murine oviductal fluid contains extracellular vesicles (EVs), called oviductosomes (OVS). During proestrus/estrus these oviductosomes carry and deliver to sperm an essential fertility-modulating protein, plasma membrane $\mathrm{Ca} 2+$-ATPase 4 (PMCA4). Interestingly, previous genetic evidence has shown that the deletion of PMCA4 disrupts $\mathrm{Ca} 2+$ homeostasis and leads to loss of both progressive and hyperactive sperm motility leading to infertility in these knockout mice $[45,46]$. Moreover, PMCA4 is synthetized and secreted in the murine epididymis with higher secretion levels in the caudal epididymis rather than the caput [47] where spermatozoa are immotile [48].The previously described findings support the idea that additional levels of PMCA4 secreted in female tracts, particularly in oviductosomes, might be important for physiological control of sperm capacitation, hyperactivation and the acrosome reaction $[44,49]$ all requiring an elevated level of $\mathrm{Ca} 2+[50-53]$.

\section{Relevancy of the seminal proteins associated to fertility and use of frozen semen}

Equine spermatozoa induce a physiologic inflammatory response in the mares reproductive tract $[5,21]$. Insemination with frozen/thawed semen induces greater inflammation when compared to raw, fresh semen [22]. This is due to the modulatory effects that seminal plasma has on the arrival of PMN cells into the uterine lumen after insemination, controlling the extent of uterine inflammation [21,23]. Removal of seminal plasma prior to freezing makes spermatozoa more vulnerable to attack by PMN in the uterine environment resulting in higher chemotaxis after insemination. This in turn results in fewer spermatozoa to reaching the oviduct when AI is performed with frozen semen in comparison with fresh semen [21]. Considering that, frozen/thawed spermatozoa are more sensitive to capacitation inducers then fresh semen [16], has a sense, that certain factors in fresh semen can protect the spermatozoa from spontaneous capacitation. Although differences in type and family of the proteins that have been identified between several species, the current view is that their role in fertilization process are essentially conserved [54]. Most of these SP proteins have been usually classified into three major families: 


\section{Global Journal of Reproductive Medicine}

i. The cysteine-rich secretory proteins (CRISP),

ii. Proteins containing the fibronectin type II domain (Fn2, also known as bovine seminal plasma proteins or BSP) and

iii. The spermadhesins [55].

The CRISP seminal plasma proteins have been described in several species including human [56], boar [56,57] and stallion [10]. The role of CRISP in sperm function it is not clear, but there is some evidence to suggest their ability to inhibit $\mathrm{Ca} 2+$ flow through the regulation of ryanodine receptor. In addition, a hypothesized role for CRISP2 has been suggested in the modulation of flagellar activity [58] or as a decapacitation factor for CRISP 1 [59].

Recently, a possible role in the modulation of sperm-oocyte binding has been identified in the rat and mouse by CRISP1 and CRISP2 [56] and has been shown that CRISP1 and CRISP2 bind irreversibly to the sperm membrane and migrate to the fusogenic region of the sperm head after capacitation and acrosome reaction [60]. Furthermore, in vitro fertilization assays showed that the exposure of spermatozoa to CRISP1 or CRISP2 antibodies reduced their ability to penetrate the oocyte $[61,62]$, an effect that was confirmed using CRISP1 knockout mice. Da Ros et al. [63] showed that CRISP1(-/-) sperm had a reduced ability to penetrate the zona pellucida and adhere to the oocyte plasma membrane compared to wild type sperm [63]. Another member of this protein group that is present in high amounts in stallions is CRISP3 [10] and there is evidence demonstrating a possible association between CRISP3 and in vivo fertility in stallions [64]. Furthermore, CRISP3 polymorphisms leading to an amino acid substitution from glutamic acid lysine at position 208 have been associated with decreased fertility rates [65]. An abundance of CRISP3 in the SP was positively correlated to first cycle conception rate [66]. These results suggest that CRISP3 could be used as a possible biomarker of sperm quality in stallions [64].

The Fibronectin-2 type proteins (Fn-2) are a family of proteins that were firstly described as a major protein present in bovine seminal plasma, and were called the binder of sperm (BSP) proteins. They represent the major secretion of the bovine seminal vesicles and bind to sperm with which they come into contact $[67,68]$. Homologs of bovine BSP proteins have been identified in several other mammalian species including humans [69], boar and stallions [70]. Recently, Ardon \& Suarez [71] have reported that the frozen/thawed bull spermatozoa have higher levels of BSP proteins (BSP1, BSP3, and BSP5) and less BSP3 bounded than on fresh sperm. Interestingly, the authors showed that reduction of BSP3 from 15 to $13 \mathrm{kDa}$ in mass during incubation of sperm under mild capacitating conditions was enhanced by cryopreservation. BSP proteins also play a role in capacitation [72,73] and are required for sperm to bind to oviductal epithelium in the storage reservoir.

Excess BSP proteins seem to exert a negative effect on the fertilization capacity of sperm, possibly modifying the timing of capacitation and thereby reducing the chance that capacitated sperm would be available to fertilize oocytes during the small window of time when fertilization is optimal [71]. There is also evidence that BSP1 prolongs bull sperm viability by acting to stabilize plasma membranes [74]. It was demonstrated that adding BSP1 to phospholipid membranes reduces membrane fluidity and immobilizes cholesterol in artificial membrane and in epididymal spermatozoa [75,76]. BSP1 can also stabilize plasma membranes by inhibiting of phospholipase A2 [77]. In summary, BSP1 could serve to stabilize sperm membranes when bound to oviductal receptors [74]. For other hand, the horse seminal plasma proteins (HSP) such as, HSP1, HSP2, HSP5 and HSP8 can bind to heparin and recognize the surface of spermatozoa $[10,19]$. The HSP1 and HSP have heparin-binding capacity. In addition, both have showed to modulate the sperm plasma membrane, suggesting a regulative role of the capacitation process [10].

The BSP proteins present in seminal plasma intrinsically remove sperm membrane lipids and this is detrimental to sperm storage in the liquid or frozen states [78]. In this regard, is fascinatingly that BSP proteins associate with low-density lipoprotein present in egg yolk extender as well as caseins and whey proteins present in milk extender. This association prevents or minimizes lipid loss from the sperm membrane thereby protecting sperm during cold storage. The spermadhesins are another group of seminal plasma proteins that are expressed in the male genital tract of pig, horse and bull and have been found to be peripherally associated to the sperm surface [79]. They are multifunctional proteins with a wide range of ligand abilities, from heparin to phospholipids of the sperm membrane that change with glycosylation and aggregations states [64]. At the functional level has been showed that low-weight zinc-binding SP proteins, probably members of spermadhesin family, protect against the damaging effects of cold shock [80]. The addition of the Heparin-binding (HBP) fraction of seminal plasma to boar spermatozoa was able to prevent in vitro capacitation and cooling-induced capacitation-like changes [81], and has been suggested that the role of these proteins would be to allow the sperm to reach the oviduct in a non-capacitated, functionally competent state [64]. To date, in stallions, the only spermadhesin protein described has been HSP7, with a role assigned in the sperm binding to the zona pellucid of the oocyte [82].

\section{Sperm-oviduct interaction}

In order to complete fertilization, the spermatozoon must survive the uterine environment, be transported to the oviduct, and be prepared to penetrate the oocyte after completing capacitation [21]. Observations regarding to the transport of spermatozoa in the mare reproductive tract after insemination have shown that it takes approximately 4 hours to reach the oviduct [19,22]. For other hand, has been showed that the isthmus is a spermatic reservoir, to which the sperms bind through the oviductal epithelium. This reservoir has the duty of protecting spermatozoa against phagocytosis by PMN, preserving their viability $[7,8]$ and slowing the process of capacitation, a 


\section{Global Journal of Reproductive Medicine}

phenomenon which seems to depend on the interaction between sperm and OEC $[5,6]$. The sperm cells stored in the reservoir are released around the time of ovulation to participate in the fertilization of the oocyte [19]. In horses, it has been reported that the combination of estradiol and HE increases the in vitro liberation of sperm from the OEC, suggesting that the release of follicular fluid in to the oviduct at the time of ovulation could initiate the detachment of sperm from the OEC [19]. The extent of spermatic storage and survival in the mare oviduct must be stressed since pregnancies have been reported from a single mating or insemination as much as 6 days prior to ovulation $[6,19,83]$. This reflects on the capacity of the oviduct to store a viable sperm population $[6,34]$.

For an adequate sperm-oviduct interaction, it is necessary that the sperm cells remain viable, motile and are morphologically normal [83]. Scanning electron microscopy studies have shown that more than $90 \%$ of sperm found in the oviduct are morphologically normal, and therefore potentially fertile [5] This has been observed even after insemination with a high percentage of morphologically defective sperm, which insinuates that most of these do not reach the oviduct or do not interact with the oviductal epithelium during transport throughout mare's reproductive tract $[22,83]$. Defective sperm may undergo phagocytosis by PMN; it is not yet clear whether or not this is a selective process [23]. Additionally, the morphologic damage suffered by the spermatic membrane during freezing and thawing reduces the number of spermbinding to $\mathrm{OEC}[17,84]$ and to homologous ZP in-vitro [17]. This may occur because capacitated, unviable or morphologically altered spermatozoa do not traverse the utero-tubal papillae or interact with the OEC $[7,84]$. This may be due to cryocapacitation, premature capacitation or acrosomal reactions that occur before insemination due to instability of the spermatozoon cell membrane [11]. Spermatic viability may be extended during oviductal storage by means of reduction in spermatic intracellular calcium [8]. In order to investigate this, an in vitro study demonstrated that sperm released from OEC after 4 hours of incubation had a higher concentration of calcium compared to sperm still joined to OEC. Thus, a low concentration of calcium may delay capacitation [8]. Similar results were obtained in a study of joint incubation of frozen/thawed sperm and OEC monolayers which showed that sperm in contact with OEC maintained their viability for up to four days, whereas sperm incubated without OEC remained viable for less than 24 hours [7].

A positive correlation has been reported between sperm motility and sperm morphology, as well as a negative correlation between sperm motility and sperm with midpiece morphological abnormalities [85]. This suggests that those sperm, with normal morphology, are motile and able to move lineally and rapidly. Spermatozoa with midpiece abnormalities are associated to ejaculates with low motility, non-progressive movements and a reduced speed [85]. When comparing sperm viability and sperm motility of fresh and frozen semen (diluted in skim milk with added glucose) in joint incubation with OEC, frozen/thawed sperm were less viable $(61.6 \pm 16.3 \%)$ than fresh sperm $(81.9 \pm 8.4 \%)$. Frozen/thawed sperm had reduced motility $(43.8 \pm 10.5 \%)$ compared to fresh sperm $(82.1 \pm 6.2 \%) 30$ minutes after thawing or ejaculation, respectively. However, the loss of motility observed through time in sperm bound to OEC was not different after 48 hours between frozen/thawed and fresh sperm [17].

Changes in spermatic cell membrane in frozen semen may impede proper contact between sperm and OEC, diminishing the number of motile frozen/thawed sperm that bind to OEC [16]. Hence, frozen/thawed sperm may have a reduced probability of achieving fertilization of the oocyte due to their decreased capacity to penetrate the ZP, impaired longevity and a lower concentration of functional sperm reaching the oviduct $[7,16]$ Interestingly, Dobrinski et al. [17] compared frozen/thawed semen with fresh semen diluted in a freezing medium. Their results were adjusted according to motility and membrane integrity (viability), and a difference was observed regarding frozen/thawed sperms capacity to bind to OEC. This effect seems to be independent of spermatic motility, cell membrane integrity $[17,84]$ and acrosomal state [84]. Thus, it appears that other, still undefined changes may adversely affect frozen/thawed spermatic binding to OEC [84]. The authors hypothesized that changes or alterations of spermatic cell membrane receptors, could be responsible for the binding of sperm to OEC $[17,84]$. Altogether, this information suggests that spermatic selection occurs at the site of the spermatic union with OEC [84].

Research in bulls, pigs and horses indicates that carbohydrate recognition may be an important part of the interaction between sperm and the oviduct, suggesting that carbohydrate-binding proteins or lectins mediate at least part of this interaction [86] Carbohydrate residues, recognized by sperm carbohydratebinding proteins, vary according to species [86]. In the case of cattle, fucosyl residues interact with the sperm protein called PDC-109.In the pig, galactose and mannose are recognized by AQN1or heparin-binding DQH $[19,86]$. Furthermore, in humans it is still unknown which sperm receptors are involved in the sperm-oviduct interaction [87]. In the mare oviduct, the most frequently found glycoconjugates are galactosyl residues, which may represent the corresponding ligand for sperm adhesion in the equine oviduct [19], and has been reported that addition of galactose or glycoproteins with exposed galactosyl residues to equine sperm-OEC co-cultures, inhibits sperm attachment to the cells $[19,24]$.

The expression of such galactosyl residues is inconsistent during the mare's estrous cycle [19], and has been reported that during estrus, the expression of galactosyl residues is greater in the isthmus than in the ampulla and that a greater number of sperm attached to oviductal explants were obtained [19]. Moreover, in the rostral part of the sperm head, a protein of galactose union has been described, representing a possible candidate to the sperm-OEC union [86]. However, a recent study 


\section{Global Journal of Reproductive Medicine}

in cats concluded that some of the sperm joined the oviductal explants by the tail [88].

\section{Conclusion}

The isthmic oviductal region has important roles in the protection against sperm phagocytosis, preservation of sperm viability, regulation of the capacitation process, and finally, synchronizing a temporary window for ovulation and fertilization. There is evidence to suggest that seminal and oviductal proteins have a key role in the temporary control of sperm-oviduct interaction. As a result of this interaction, the sperm are recognized and differentiated according to integrity, stored in metabolic arrest and are finally released to undergo sperm capacitation, acrosome reaction, and a with hyperactive motility to achieve fertilization of the oocyte. The remotion of seminal plasma to sperm cryopreservation, alter or change the normal binding between seminal plasma proteins and surface of sperm. As effect of this remotion, the frozen sperm has a lower ability to interact with oviductal epithelial cells and later achieve fertilization.

More studies, with a molecular and cellular focus, are required to clarify which specific components are required to preserve the sperm-oviduct interaction in the mare following cryopreservation of sperm and how seminal plasma components could minimize the cryoinjury.

\section{Acknowledgement}

The authors thank Dr. Jennifer Clulow for the editing support.

\section{References}

1. De Oliveira CH (2007) Avaliação das características do espermatozoideequino congelado submetido a inclusão e remoção do colesterol das membranas. Título de Mestre em Medicina Veterinária. 2007. Escola de Veterinária. Universidade federal de Minas Gerais, Brasil.

2. Squires EL (2009) Changes in equine reproduction: Have they been good or bad for the horse industry? J EquineVetSci 29(5): 268-273.

3. Brass K (2001) Inseminación artificial en la especie equina. In: Palma GA, editor. Biotecnología de la Reproducción. Buenos Aires: INTA pp. 525-557.

4. McKinnon A (2010) Assisted Reproduction Techniques (ART) in the horse - a review from artificial insemination to cloning. Proceedings of the $49^{\text {th }}$ British Equine Veterinary Association Congress BEVA, Birmingham; pp. 105-106.

5. Rodríguez-Martínez H (2006) Modulation of sperm function during sperm transport in the female. JIFS 3: 73-83.

6. Desantis S, Zizza S, Accoglia G, Aconeb F, Rossic R, et al. (2011) Morphometric and ultrastructural features of the mare oviduct epithelium during oestrus. Theriogenology 75(4): 671-678.

7. Thomas PG, Ball BA, Miller PG, Brinsko SP, Southwood L (1994) A subpopulation of morphologically normal, motile spermatozoa attach to equine oviductal epithelial cell monolayers. BiolReprod 51(2): 303309 .

8. Dobrinski I, Smith TT, Suarez SS, Ball BA (1997) Membrane contact with oviductal epithelium modulates the intracellular calcium concentration of equine spermatozoa in-vitro. BiolReprod 56(4): 861-869.
9. Gadella BM, Rathi R, Brouwers JFHM, Stout TAE, Colenbrander B (2001) Capacitation and the acrosome reaction in equine sperm. Anim Reprod Sci 68(3-4): 249-265.

10. Töpfer PE, Ekhlasi HM, Kirchhoff C, Leeb T, et al. (2005) The role of stallion seminal proteins in fertilization. AnimReprod Sci 89(1-4): 159170 .

11. Neild DN, Gadella BM, Agüero A, Stout TAE, Colenbrander B (2005) Capacitation, acrosome function and chromatin structure in stallion sperm. AnimReprod Sci 89(1-4): 47-56.

12. Samper JC (2009) Artificial insemination with fresh and cooled semen. In: Samper JC (Ed), Equine breeding management and artificial insemination. Missouri: W.I.B. Saunders pp. 165-174.

13. Squires EL, Pickett BW, Graham JK, Vanderwall DK, McCue PM, et al (1999) Introduction of frozen semen. In: Squires EL, Pickett BW, Graham JK (Eds), Cooled and frozen stallion semen. Colorado: Colorado State University, Colorado, USA pp. 39-41.

14. Morris GJ, Faszer K, Green JE, Draper D, Grout BWW, et al. (2007) Rapidly cooled horse spermatozoa: Loss of viability is due to osmotic imbalance during thawing, not intracellular ice formation. Theriogenology 68(5): 804-812.

15. Morris GJ, Acton E, Murray BJ, Fonseca F (2012) Freezing injury: The special case of the sperm cell. Cryobiology 64(2): 71-80.

16. Sieme H, Harrison RAP, Petrunkina AM (2008) Cryobiological determinants of frozen semen quality, with special reference to stallion. Anim Reprod Sci 107(3-4): 276-292.

17. Dobrinski I, Thomas PGA, Ball BA (1995) Cryopreservation reduces the ability of equine spermatozoa to attach to oviductal epithelial cells and zona pellucidae in-vitro. J Androl 16(6): 536-542.

18. Thomas AD, Meyers SA, Ball BA (2006) Capacitation-like changes in equine spermatozoa following cryopreservation. Theriogenology 65(8): 1531-1550.

19. Ball BA (2011) Sperm-oviduct interaction. In: McKinnon A, Squires EL, Vaala WE, et al. (Eds.), Equine reproduction ( $\left.2^{\text {nd }} e d n\right)$ Iowa: WileyBlackwell, USA pp. 1085-1091.

20. Dobrinski I, Suarez SS, Ball BA (1996) Intracellular calcium concentration in equine spermatozoa attached to oviductal epithelial cells in vitro. BiolReprod 54(4): 783-788.

21. Crabo BG (2001) Physiological aspects of stallion semen cryopreservation. Proceeding of the $47^{\text {th }}$ Annual Convention of the AAEP, San Diego 4: 291-295.

22. Troedsson MHT, Liu IKM, Crabo BG (1998) Sperm transport and survival in the mare: A review. Theriogenology 50(5): 807-818.

23. Troedsson MHT, Loset K, Alghamdi AM, Dahms B, Crabo BG (2001) Interaction between equine semen and the endometrium: the inflammatory response to semen. Anim Reprod Sci 68(3-4): 273-278.

24. Bosch P, Wright RW (2005) The oviductal sperm reservoir in domestic mammals. Arch Med Vet 37(2): 95-104.

25. Aguilar J, Reyley M (2005) The uterine tubal fluid: secretion, composition and biological effects. Anim Reprod 2(2): 91-105.

26. Desantis S, Ventriglia G, Zizza S, Guaricci AC, Losurdo M, et al. (2010) Changes in the expression of the $\mu$-opioid receptor in the mare oviduct during oestrus and anoestrus. Anim Reprod Sci 119(1-2): 40-49.

27. Aguilar JJ, Cuervo AJ, Mouguelar H, Losinno L (2012) Histological Characteristics of the Equine Oviductal Mucosa at Different Reproductive Stages. J Equine Vet Sci 32(2): 99-105.

28. Killian GJ (2004) Evidence for the role of oviduct secretions in sperm function, fertilization and embryo development. AnimReprod Sci 8283: $141-53$. 


\section{Global Journal of Reproductive Medicine}

29. Mugnier S, Kervella M, Douet C, Canepa S, Pascal G, et al. (2009) The secretions of oviduct epithelial cells increase the equine in vitro fertilization rate: are osteopontin, atrial natriuretic peptide $\mathrm{A}$ and oviductin involved? Reprod Biol Endocrin 7: 129-145.

30. Rodríguez MH (2007) Role of the oviduct in sperm capacitation. Theriogenology 68(1): S138-146.

31. Rodriguez HI, Stewart AJ, Wolfe DF, Caldwell FJ, Harrie M, et al. (2011) Immunolocalization of the hyaluronan receptor CD44 in the reproductive tract of the mare. Theriogenology 75(2): 276-286.

32. Yániz J (1999) Estudio sobre la estructura y función de la mucosa oviductal y el mesotelio peritoneal de la vaca. Memoria para optar al grado de doctor. Departamento de Producción Animal. Facultad de Ingenería Agronómica. Universitat de Lleida, España.

33. Risopatrón J, Catalán S, Sepúlveda N, Sánchez R (2005) Efecto de diferentes concentraciones de heparina sobre la capacitación espermática in-vitro en canino. Rev Cient-Fac Cien XV: 528-535.

34. Kimura H, Matsuda J, Ogura A, Asano T, Naiki M (1994) Affinity binding of hamster oviductin to spermatozoa and its influence on in vitro fertilization. Mol Reprod Dev 39(3): 322-327.

35. Saccary L, She YM, Oko R, Kan FW (2013) Hamster oviductin regulates tyrosine phosphorylation of sperm proteins during in vitro capacitation. BiolReprod 89(2): 38-49.

36. Kan FW, Esperanzate PW (2006) Surface mapping of binding of oviductin to the plasma membrane of golden hamster spermatozoa during in vitro capacitation and acrosome reaction. Mol Reprod Dev 73(6): 756-766.

37. Gabler C, Chapman DA, Killian GJ (2003) Expression and presence of osteopontin and integrins in the bovine oviduct during the oestrus cycle.Reproduction 126: 721-729.

38. Yeung WS, Lee KF, Koistinen R, Koistinen H, Seppala M, et al. (2006) Roles of glycodelin in modulating sperm function. Mol Cell Endocrino 1250: 149-56.

39. Ghersevich S, Massa E, Zumoffen C (2015) Oviductal secretion and gamete interaction. Reproduction 149(1): R1-R14.

40. Dutta B, Ain R, Seshagiri PB, Karande (2001) Differential influence of recombinant non-glycosylated and glycosylated glycodelin on human sperm function: comparative studies with hamster spermatozoa. Reprod Fertil Dev 13(2-3): 111-118.

41. Oehninger S, Coddington CC, Hodgen GD, Seppala M (1995) Factors affecting fertilization: endometrial placental protein 14 reduces the capacity of human spermatozoa to bind to the human zona pellucida. FertilSteril 63(2): 377-383.

42. Chiu PC, Koistinen R, Koistinen H, Seppala M, Lee KF, et al. (2003) Zonabinding inhibitory factor-1 from human follicular fluid is an isoform of glycodelin. BiolReprod 69(1): 365-372.

43. Yeung WS, Lee KF, Koistinen R, Koistinen H, Seppala M, et al. (2007) Glycodelin: a molecule with multi-functions on spermatozoa. Society ReprodFert Supp 63: 143-151.

44. Al-Dossary AA, Bathala P, Caplan J L, Martin-DeLeon PA (2015) Oviductosome-Sperm Membrane Interaction in Cargo Delivery: Detection of Fusion and Underlying Molecular Players using 3D SuperResolution Structured Illumination Microscopy (SR-SIM). J Biol Chem 290(29): 17710-17723.

45. Okunade GW, Miller ML, Pyne GJ, Sutliff RL, O'Connor KT, et al. (2004) Targeted ablation of plasma membrane Ca2-ATPase (PMCA) 1 and 4 indicates a major housekeeping function for PMCA1 and a critical role in hyperactivated sperm motility and male fertility for PMCA4. J Biol Chem 279(32): 33742-33750.

46. Schuh K, Cartwright EJ, Jankevics E, Bundschu K, Liebermann J, et al. (2004) Plasma membrane Ca2_ATPase 4 is required for sperm motility and male fertility. J Biol Chem 279: 28220-28226.
47. Patel R, Al-Dossary AA, Stabley DL, Barone C, Galileo DS, et al. (2013) Plasma membrane $\mathrm{Ca}^{2+}$ ATPase 4 in murine epididymis: secretion of splice variants in the luminal fluid and a role in sperm maturation. BiolReprod 89(1): 6.

48. Yeung CH, Cooper TG (2002) Acquisition and development of sperm motility upon maturation in the epididymis. In: Robaire B, Hinton BT (Eds), The Epididymis: From Molecules to Clinical Practice, Kluwer Academic/Plenum Publishers, New York, USA, pp. 417-434.

49. Al-Dossary AA, Strehler EE, Martin-DeLeon PA (2013) Expression and secretion of plasma membrane $\mathrm{Ca}^{2+}$ ATPase $4 \mathrm{a}$ (PMCA4a) during murine estrus: association with oviductal exosomes and uptake in sperm. PloS one 8(11): e80181.

50. Gadella BM, Luna C (2014) Cell biology and functional dynamics of the mammalian sperm surface. Theriogenology 81(1): 74-84.

51. Ho HC, Granish KA, Suarez SS (2002) Hyperactivated motility of bull sperm is triggered at the axoneme by $\mathrm{Ca}^{2+}$ and not cAMP. Dev Biol 250(1): 208-217.

52. Ho HC, Suarez SS (2003) Characterization of the intracellular calcium store at the base of the sperm flagellum that regulates hyperactivated motility. BiolReprod 68(65): 1590-1596.

53. Suarez SS, Ho HC (2003) Hyperactivation of mammalian sperm. Cell Mol Biol 49(3): 351-356.

54. Calvete JJ, Sanz L (2007) Insights into structure-function correlations of ungulate seminal plasma proteins. Soc Reprod Fertil Suppl 65: 201 215.

55. Rodríguez MH, Kvist U, Ernerudh J, Sanz L, Calvete JJ (2011) Seminal plasma proteins: what role do they play?. Am J ReprodImmunol 66(s1): $11-22$.

56. Koppers AJ, Mitchell LA, Wang P, Lin M, Aitken RJ (2011) Phosphoinositide 3-kinase signalling pathway involvement in a truncated apoptotic cascade associated with motility loss and oxidative DNA damage in human spermatozoa. Biochem J 436(3): 687-698.

57. Vadnais ML, Foster DN, Roberts KP (2008) Molecular cloning and expression of the CRISP family of proteins in the boar. Biol Reprod 79(6): 1129-1134.

58. Gibbs GM, Scanlon MJ, Swarbrick J, Curtis S, Gallant E, et al. (2006) The cysteine-rich secretory protein domain of tpx-1 is related to ion channel toxins and regulates ryanodine receptor $\mathrm{Ca}^{2+}$ signaling. J Biol Chem 281(7): 4156-4163.

59. Roberts KP, Wamstad JA, Ensrud KM, Hamilton DW (2003) Inhibition of capacitation-associated tyrosine phosphorylation signaling in rat sperm by epididymal protein Crisp-1. BiolReprod 69(2): 572-581.

60. Da Ros VG, Munuce MJ, Cohen DJ, Marín BCI, Busso D, et al. (2004) Bicarbonate is required for migration of sperm epididymal protein DE (CRISP-1) to the equatorial segment and expression of rat sperm fusion ability. BiolReprod. 70(5): 1325-1332.

61. Cohen DJ, Ellerman DA, Busso D, Morgenfeld MM, Piazza AD, et al (2001) Evidence that human epididymal protein ARP plays a role in gamete fusion through complementary sites on the surface of the human egg. BiolReprod. 65(4): 1000-1005.

62. Busso D, Cohen DJ, Maldera JA, Dematteis A, Cuasnicu PS (2007) A novel function for CRISP1 in rodent fertilization: involvement in sperm-zona pellucida interaction. BiolReprod 77(5): 848-854.

63. Da Ros VG, Maldera JA, Willis WD, Cohen DJ, Goulding EH, et al. (2008) Impaired sperm fertilizing ability in mice lacking Cysteine-Rich Secretory Protein 1 (CRISP1). Dev Biol 320(1): 12-18.

64. Caballero I, Parrilla I, Almiñana C, del Olmo D, Roca J, et al. (2012) Seminal plasma proteins as modulators of the sperm function and their application in sperm biotechnologies. Reprod Domest Anim 47(s3): 12-21. 


\section{Global Journal of Reproductive Medicine}

65. Hamann H, Jude R, Sieme H, Mertens U, Töpfer PE, et al. (2007) A polymorphism within the equine CRISP3 gene is associated with stallion fertility in Hanoverian warmblood horses. Anim Genet 38(3): 259-264.

66. Novak S, Smith TA, Paradis F, Burwash L, Dyck MK, et al. (2010) Biomarkers of in vivo fertility in sperm and seminal plasma of fertile stallions. Theriogenology 74(6): 956-967.

67. Desnoyers L, Manjunath P (1992) Major proteins of bovine seminal plasma exhibit novel interactions with phospholipid. J Biol Chem 267(14): 10149-10155.

68. Manjunath P, Lefebvre J, Jois PS, Fan J, Wright MW(2009) New nomenclature for mammalian BSP genes. BiolReprod. 80(3): 394-397.

69. Lefebvre J, Boileau G, Manjunath P(2009) Recombinant expression and affinity purification of a novel epididymal human sperm-binding protein, BSPH1. Mol Hum Reprod 15(2): 105-114.

70. Calvete JJ, Raida M, Gentzel M, Urbanke C, Sanz L, et al. (1997) Isolation and characterization of heparin- and phosphorylcholine binding proteins of boar and stallion seminal plasma. Primary structure of porcine pB1. FEBS letters. 407(2): 201-216.

71. Ardon F, Suarez SS (2013) Cryopreservation increases coating of bull sperm by seminal plasma binder of sperm proteins BSP1, BSP3, and BSP5. Reproduction 146(2): 111-117.

72. Lane ME, Therien I, Moreau R, Manjunath P (1999) Heparin and highdensity lipoprotein mediate bovine sperm capacitation by different mechanisms. BiolReprod 60(1): 169-175

73. Manjunath P, Therien I (2002) Role of seminal plasma phospholipidbinding proteins in sperm membrane lipid modification that occurs during capacitation. J ReprodImmunol 53(1): 109-119.

74. Suarez SS (2016) Mammalian sperm interactions with the female reproductive tract. Cell Tissue Res 363(1): 185-194.

75. Greube A, Muller K, Töpfer PE, Herrmann A, Muller P (2014) Influence of the bovine seminal plasma protein PDC-109 on the physical state of membranes. Biochemistry 40(28): 8326-8334.

76. Müller P, Greube A, Töpfer P E, Herrmann A (2002) Influence of the bovine seminal plasma protein PDC-109 on cholesterol in the presence of phospholipids. EurBiophys J 31(6): 438-447.
77. Soubeyrand S, Manjunath P (1997) Novel seminal phospholipase A 2 is inhibited by the major proteins of bovine seminal plasma. Bba-Protein Struct M 1341(2): 183-188.

78. Manjunath P (2012) New insights into the understanding of the mechanism of sperm protection by extender components. Anim Reprod Sci 9(4): 809-815.

79. Töpfer PE, Romero A, Varela PF, Ekhlasi-Hundrieser M, Dostalova Z, et al. (1998) Spermadhesins: A new protein family.Facts, hypotheses and perspectives. Andrologia 30(4-5): 217-224.

80. Mogielnicka BM, Wysocki P, Strzezek J, Kordan W (2011) Zincbinding proteins from boar seminal plasma-isolation, biochemical characteristics and influence on spermatozoa stored at $4 \mathrm{C}$. ActaBiochim Pol 58:171-177.

81. Vadnais ML, Roberts KP (2010) Seminal plasma proteins inhibit in-vitro and cooling-induced capacitation in boar spermatozoa. ReprodFert Develop 22(6): 893-900.

82. Reinert M, Calvete JJ, Sanz L, Töpfer-Petersen E (1997) Immuno histochemical localization in the stallion genital tract, and topography on spermatozoa of seminal plasma protein SSP-7, a member of the spermadhesin protein family. Andrologia 29(4): 179-186.

83. Scott MA (2000) A glimpse at sperm function in vivo: sperm transport and epithelial interaction in the female reproductive tract. Anim Reprod Sci 60-61: 337-48.

84. Thomas PGA, Ball BA (1996) Cytofluorescent assay to quantify adhesion of equine spermatozoa to oviduct epithelial cells in vitro. MolReprod Dev 43(1): 55-61.

85. Love CC (2011) Relationship between sperm motility, morphology and the fertility of stallions. Theriogenology 76(3): 547-57.

86. Sabeur K, Ball BA (2007) Characterization of galactose-binding proteins in equine testis and spermatozoa. Anim Reprod Sci 101(1-2): 74-84.

87. Huang VW, W Zhao, CL Lee, CYL Lee, KKW Lam, et al. (2013) Cell membrane proteins from oviductal epithelial cell line protect human spermatozoa from oxidative damage. Fertil Steril 99(5): 1444-14452.

88. Henry F, Eder S, Reynaud K, Schön J, Wibbelt G, et al. (2015) Seminal fluid promotes in-vitro sperm-oviduct binding in the domestic cat (Felis catus). Theriogenology 83(8): 1373-1380.

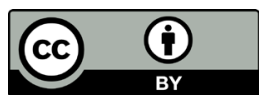

This work is licensed under Creative Commons Attribution 4.0 Licens DOI:_10.19080/GJORM.2017.03.555601

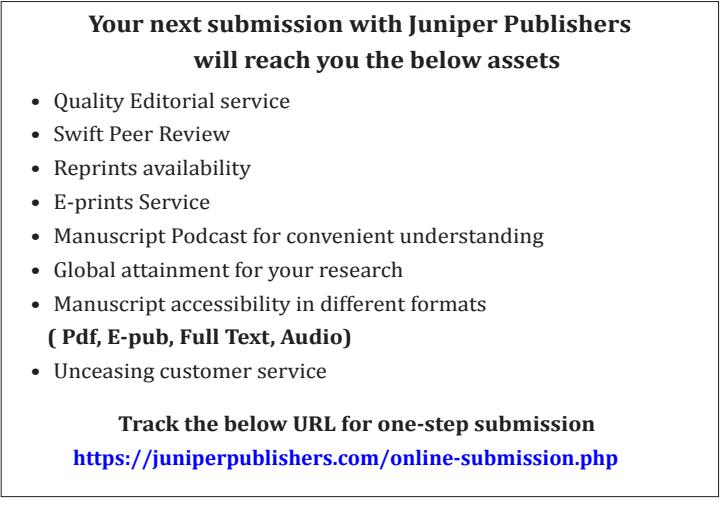

